\title{
Multicriterial evaluation and optimization of an algorithm for charging energy storage elements
}

\author{
Krasimir Kishkin *, Dimitar Arnaudov *, Venelin Todorov ${ }^{\dagger \ddagger}$, Sefka Fidanova ${ }^{\ddagger}$ \\ ${ }^{*}$ Technical University of Sofia 8 Kliment Ohridski blvd., 1000 Sofia, Bulgaria \\ ${ }^{\dagger}$ Institute of Mathematics and Informatics \\ Bulgarian Academy of Sciences \\ 8 Acad. G. Bonchev Str., 1113 Sofia, Bulgaria \\ ${ }^{\ddagger}$ Institute of Information and Communication Technologies \\ Bulgarian Academy of Sciences \\ 25A Acad. G. Bonchev Str., 1113 Sofia, Bulgaria
}

Email: k.kishkin@abv.bg, dda@tu-sofia.bg, vtodorov@math.bas.bg, venelin@ parallel.bas.bg, stefka@parallel.bas.bg

\begin{abstract}
This study compares optimized active voltage balancing algorithms, applicable for energy storage systems made of supercapacitor cells connected in series. The results presented herein are obtained from a simulation model and confirmed on an experimental stand.
\end{abstract}

\section{INTRODUCTION}

$\mathbf{N}$ OWADAYS, the most widely used elements for energy storage systems (ESS) are either Li-Ion cells or Supercapacitor cells. The control system or the Battery Management System (BMS) [1] has the task to charge and discharge them and manufactured a battery pack without any damage due to over voltages or over currents. Nowadays all BMSs use active voltage balancing techniques based on different methods [2]-[7].

\section{A SHORT DESCRIPTION OF THE STUDIED ENERGY STORAGE SYSTEM}

A simplified block diagram of the studied energy storage system (ESS) is shown in Fig. 1.

The DC/DC converters linked in parallel to each cell are additional charging sources (ACS). The DC/DC converter linked in parallel to the whole string is a main charging source (MCS). $I_{\text {main }}$ is the main charging current. It charges the whole battery module. $I_{a d d}$ is an additional charging current. $I_{\text {cell }}$ is the cell charging current. For more details see [8], [9]. We stress on the fact that the simulations use technical information for $58 \mathrm{~F} / 16 \mathrm{~V}$ module supercapacitor by Maxwell Technologies Inc. [10]. $t_{f c h}$ is the time necessary for the cell

Venelin Todorov is supported by KP-06-M32/2-17.12.2019 "Advanced Stochastic and Deterministic Approaches for Large-Scale Problems of Computational Mathematics" and by the National Scientific Program "Information and Communication Technologies for a Single Digital Market in Science, Education and Security" (ICTinSES), contract No. D01-205/23.11.2018, financed by the Ministry of Education and Science. The work is supported by the Bulgarian National Science Fund under Project DN 12/5-2017 "Efficient Stochastic Methods and Algorithms for Large-Scale Problems" and by the Project KP-06-Russia/17 "New Highly Efficient Stochastic Simulation Methods and Applications" funded by the National Science Fund - Bulgaria.

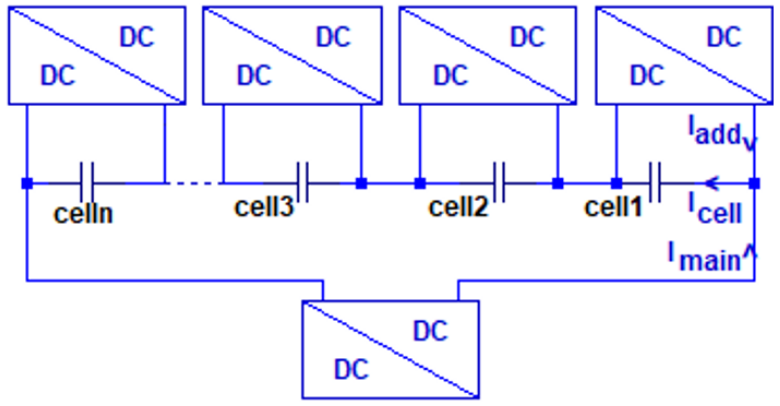

Fig. 1. ESS block diagram

with the highest capacitance $C_{\max }$ to charge from its initial voltage up to its rated voltage. It is described as

$$
t_{f c h}=f\left(C_{\max }, I_{\max }, \triangle U_{\left(C_{\max }\right)}\right) .
$$

\section{THE BASIC ALGORITHM}

In the basic algorithm (BASIC) the charging current is less than the maximum charging current $I_{\max }$.

$$
I_{\text {cell }}=I_{\text {main }}+I_{a d d}<I_{\max }
$$

$I_{\text {main }}$ and $I_{a d d}$ are strictly fixed. For each cell $C_{n}$ and $I_{a d d}$ is different and depends on the capacitance of the cell. $I_{\text {main }}$ is given by:

$$
I_{\text {main }}=I_{\max } \cdot C_{\min } / C_{\max },[A]
$$

$I_{a d d}$ is given by:

$$
I_{A C C}=I_{\max } \cdot\left(\left(C_{n}-C_{\min }\right) / C_{\max }\right),[A]
$$

Here $I_{\max }$ is the maximum charging current. $C_{n}$ is the capacitance of the n-th cell. $C_{\min }$ is the lowest capacitance and $C_{\max }$ is the highest capacitance. A detailed description of this algorithm can be found in [11]. Fig. 2 shows a typical charging process by using this algorithm. 


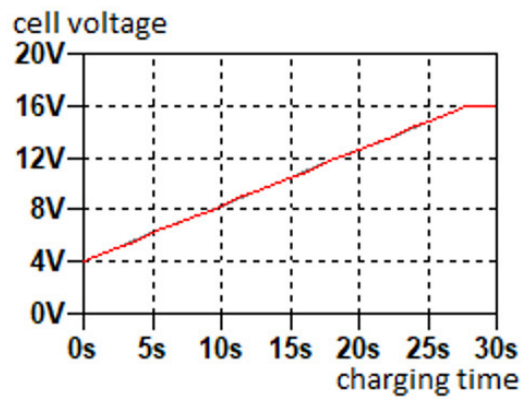

Fig. 2. Voltages across cells during charging

\section{THE OPTIMIZED ALGORITHM}

The second algorithm (OPTIMIZED) is optimized because it has a value $\triangle U$ of the voltage. It cannot be changed indefinitely. There are some optimal values, which, if skipped, result in other phenomena. Also some limit values for which the algorithm works optimally can be mentioned. Thats why for the future work we will make a $3 \mathrm{D}$ visualization, as a dependence on several quantities and to show their optimal value. The description of the optimized algorithm is described below. We begin by loading all the cells with a maximum charging current, being achieved through the synchronized work of the MCS and all ACSs which currents are equal. The charging current for each cell is:

$$
I_{\text {cell }}=I_{\text {main }}+I_{a d d}=I_{\max }
$$

A detailed description of this algorithm can be found in [12]. Fig. 3 shows a typical charging process by using this algorithm.

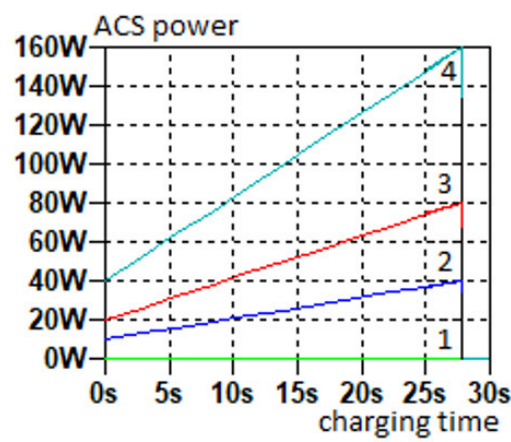

Fig. 3. Cell voltages during charging

The key point of the OPTIMIZED method is turning the ACSs off one after another and loaded the cells only by the MCS. For each cell $C_{n}$ there is a specific moment $t_{x_{\left(C_{n}\right)}}$ when its ACS is turned off. For the time from $t_{x_{\left(C_{n}\right)}}$ to $t_{f}$, the charging current is provided only from the MCS. The specific for each cell moment $t_{x}$ is given by:

$$
t_{x}=t_{f c h} \cdot\left[I_{\operatorname{main}} / I_{a d d} \cdot\left(C_{n} / C_{\max }-1\right)+C_{n} / C_{\max }\right]
$$

On Fig. 4 it is shown what happens when the capacitance difference changes.

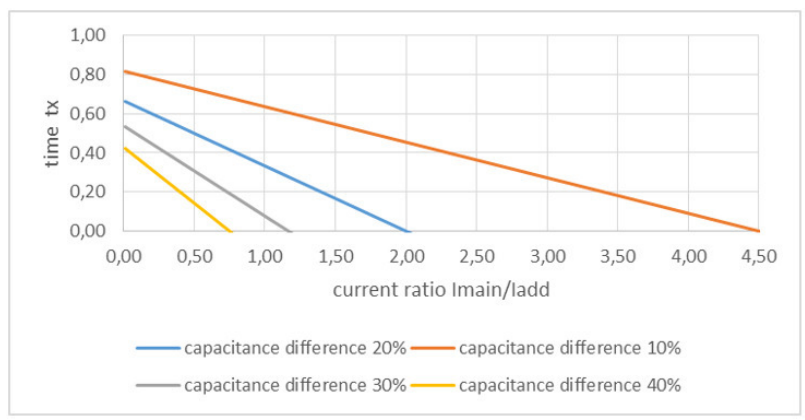

Fig. 4. $t_{x}$ as a function of $\beta$

\section{SIMULATION RESULTS AND COMPARISON OF THE STUDIED ALGORITHMS}

On Fig. 5 it is shown how the power of the additional charging sources changes.

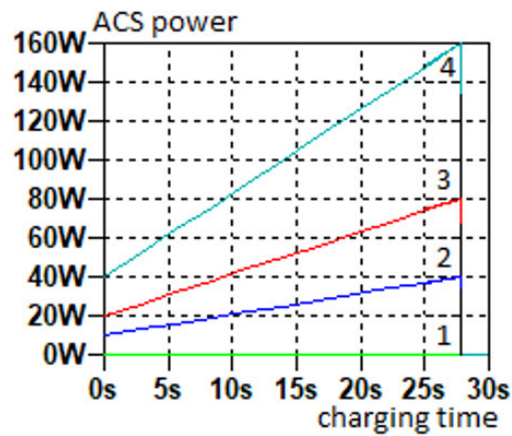

Fig. 5. ACS power

On Fig. 6 it is shown the power of the MCS.

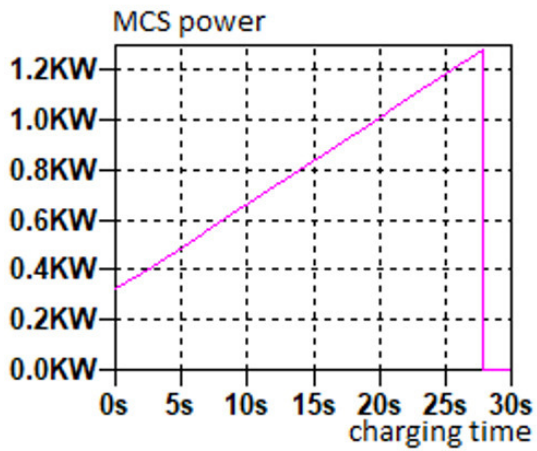

Fig. 6. MCS power

On Fig. 7 it is shown how the power of the ACSs changes during the process of charging.

Fig. 8 shows the power of the main charging source. 


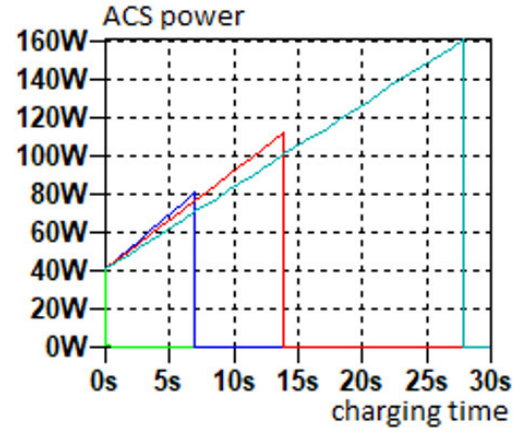

Fig. 7. ACS power

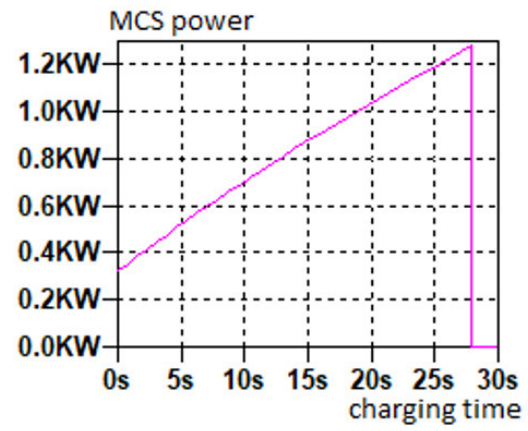

Fig. 8. MCS power

The summarized data are shown below. The notation $b$ is for the BASIC algorithm and o is for the OPTIMIZED algorithm. The OPTIMIZED method gives better results for the sources. Table 1 shows calculated values for daily mean value of consumed energy and its statistical characteristics - standard deviation, coefficient of variation, and confidence intervals at 0.95 confidence probability, where: $P_{a}-$ an average power;

TABLE I

\begin{tabular}{|c|c|c|c|c|c|c|}
\hline source & $\mathrm{Pa}[\mathrm{W}], \mathrm{b}$ & $\mathrm{Pa}[\mathrm{W}], \mathrm{o}$ & $\mathrm{Pp}[\mathrm{W}], \mathrm{b}$ & $\mathrm{Pp}[\mathrm{W}], \mathrm{o}$ & $\mathrm{E}[\mathrm{J}], \mathrm{b}$ & $\mathrm{E}[\mathrm{J}], \mathrm{o}$ \\
\hline ACS1 & 0 & 0 & 0 & 0 & 0 & 0 \\
ACS 2 & 25 & 60 & 40 & 80 & 696 & 422 \\
ACS3 & 50 & 77 & 80 & 113 & 1392 & 1066 \\
ACS4 & 100 & 101 & 160 & 160 & 2784 & 2800 \\
MCS & 800 & 827 & 1280 & 1282 & 22272 & 23019 \\
\hline
\end{tabular}

$P_{p}$ - a peak power; E -- the energy;

\section{CONCLUSION}

In the BASIC algorithm, the main charging current is fixed as a function of the cell with the lowest capacitance. A key element in the OPTIMIZED algorithm has the capacitance difference between the capacitor with the highest capacitance and the capacitor with the lowest capacitance. For the future work we will make a 3D visualization, as a dependence on several quantities and to show their optimal value.

\section{REFERENCES}

[1] D. Andrea, "Battery Management Systems for Large Lithium-Ion Battery Packs", ARTECH HOUSE 2010

[2] P. Barrade "Series connection of supercapacitors: Comparative study of solution for the active equalization of the voltages"

[3] Yasser Diab, Pascal Venet, Gerard Rojat, "Comparison of the Different Circuits Used for Balancing the Voltage of Supercapacitors: Studying Performance and Lifetime of Supercapacitors", Author manuscript, published in "ESSCAP, Lausanne: Switzerland (2006)"

[4] Chunhe CHANG, Jiangping YANG, Yu LI, Zhongni ZHU, "Research of Supercapacitor Voltage Equalization Strategy on Rubber-Tyred Gantry Crane Energy Saving System", Energy and Power Engineering, 2010 $25-30$

[5] S. Moore, P.Schneider, "A Review of Cell Equalization Methods for Lithium Ion and Lithium Polymer Battery Systems", Society of Automotive Engineers, Inc, Delphi Automotive Systems, 2001

[6] M. Daowd , N. Omar, P. Van Den Bossche, J. Van Mierlo, „Passive and Active Battery Balancing comparison based on MATLAB Simulation”, Vehicle Power and Propulsion Conference (VPPC), 2011 IEEE

[7] C. Ionescu, A. Drumea, A. Vasile and N. Codreanu, "Investigations on Active Balancing Circuits for Supercapacitor Banks," 201841 st International Spring Seminar on Electronics Technology (ISSE), Zlatibor, 2018, pp. 1-5, doi: 10.1109/ISSE.2018.8443679.

[8] D. Arnaudov, K. Kishkin and V. Dimitrov, "An Algorithm and Circuits for Active Balancing Systems," 2020 21st International Symposium on Electrical Apparatus \& Technologies (SIELA), Bourgas, Bulgaria, 2020, pp. 1-4, doi: 10.1109/SIELA49118.2020.9167066.

[9] D. Arnaudov and K. Kishkin, "Modelling and Research of Synchronous Converter for Active Balancing System," 2019 16th Conference on Electrical Machines, Drives and Power Systems (ELMA), Varna, Bulgaria, 2019, pp. 1-4, doi: 10.1109/ELMA.2019.8771689.

[10] https://files.ev-power.eu/inc/_doc/attach/StoItem/1123/ThunderSkyWinston-LIFEPO4-40Ah-Datasheet.pdf

[11] K. Kishkin, D. Arnaudov and D. Penev, "Algorithm for Charging a Supercapacitor Energy Storage System," 2020 43rd International Spring Seminar on Electronics Technology (ISSE), Demanovska Valley, Slovakia, 2020, pp. 1-6, doi: 10.1109/ISSE49702.2020.9120958.

[12] D. Arnaudov, D. Penev and K. Kishkin, "Management of Supercapacitor Battery Charging," 2020 43rd International Spring Seminar on Electronics Technology (ISSE), Demanovska Valley, Slovakia, 2020, pp. 1-7, doi: 10.1109/ISSE49702.2020.9121001. 